\title{
Genome-wide analysis of chromatin architecture in Oxytricha trifallax: a single-celled eukaryote with 16,000 tiny chromosomes
}

\author{
Leslie Y Beh*, Laura F Landweber \\ From Epigenetics and Chromatin: Interactions and processes \\ Boston, MA, USA. 11-13 March 2013
}

The pond-dwelling ciliate Oxytricha trifallax is a model system for the study of gene regulatory mechanisms. It possesses a heterochromatin-rich germline micronucleus, and a transcriptionally active somatic macronucleus (MAC). The MAC genome is highly fragmented, consisting of $>16,000$ unique "nanochromosomes", with a mean size of $3.2 \mathrm{~kb}$. Consequently, only a limited number of nucleosomes can be accommodated in short nanochromosomes. Nanochromosome size does not vary in multiples of $\sim 147 \mathrm{bp}$ corresponding to mono-nucleosome-sized DNA, suggesting that nucleosome depleted regions may be especially prevalent. This unusual genome architecture presents novel challenges for the regulation of gene expression. The efficacy and prevalence of chromatinmediated gene regulation thus remain unclear in Oxytricha. In addition, the paucity of non-coding DNA suggests that promoters in Oxytricha are highly compact, and may be organized differently from other eukaryotes. Our study aims to uncover how the chromatin structure of promoters and coding regions is constrained by chromosome length in the vegetative Oxytricha MAC. To address this, we characterize the chromatin landscape of the MAC through genome-wide mapping of nucleosome positions and DNase I hypersensitive sites. By integrating these studies with existing RNA Polymerase II ChIP-seq and mRNA-seq data, we investigate how chromatin organization varies with nanochromosome length, gene number, and transcriptional output. These data will also be coupled with transcription start site annotations to define promoter architecture in the Oxytricha MAC, including the presence and position of regulatory motifs, the distribution of transcription start sites within a promoter, and local

Department of Ecology and Evolutionary Biology, Princeton University NJ 08544, USA chromatin accessibility. Together, this integrated analysis will test the contribution of chromatin structure to gene expression regulation, and illuminate the variation of eukaryotic gene regulatory mechanisms.

Published: 18 March 2013

doi:10.1186/1756-8935-6-S1-P4

Cite this article as: Beh and Landweber: Genome-wide analysis of chromatin architecture in Oxytricha trifallax: a single-celled eukaryote with 16,000 tiny chromosomes. Epigenetics \& Chromatin 2013 6(Suppl 1): P4.

Submit your next manuscript to BioMed Central and take full advantage of:

- Convenient online submission

- Thorough peer review

- No space constraints or color figure charges

- Immediate publication on acceptance

- Inclusion in PubMed, CAS, Scopus and Google Scholar

- Research which is freely available for redistribution 